\title{
Infigratinib Mesylate
}

National Cancer Institute

\section{Source}

National Cancer Institute. Infigratinib Mesylate. NCI Thesaurus. Code C162568.

The mesylate salt of infigratinib, an orally bioavailable pan-inhibitor of human fibroblast growth factor receptors (FGFRs) with potential antiangiog enic and antineoplastic activities. Upon administration, infigratinib selectively binds to and inhibits the activities of FGFRs, which may result in the inhibition of tumor angiogenesis and tumor cell proliferation, and the induction of tumor cell death. FGFRs are a family of receptor tyrosine kinases which may be upregulated in various tumor cell types and may be involved in tumor cell differentiation and proliferation, tumor angiogenesis, and tumor cell survival. 